Niniejsza publikacja jest dostępna na licencji Creative Commons. Uznanie autorstwa-Użycie niekomercyjne-Bez utworów zależnych 3.0 Polska. Pewne prawa zastrzeżone na rzecz autora. Zezwala się na wykorzystanie publikacji zgodnie z licencjapod warunkiem zachowania niniejszej informacji licencyjnej oraz wskazania autora jako właściciela praw do tekstu. Treść licencji jest dostęna na stronie: http://creativecommons.org/licenses/by-nc-nd/3.0/pl/

Lingwistyka Stosowana 17: 2/2016, 29-41

\author{
Marta KALISKA
}

Warsaw University

\title{
An Action-Oriented Approach to Language Corpora in Foreign Language Teaching
}

\begin{abstract}
:
Since the advent of communicative approach which focuses primarily on real-life communication acts, presenting new vocabulary and grammar structures within a given context or theme, language teaching has undergone a pattern shift. The methodology has acquired more interactive and sociocultural dimension involving an active attitude of learners towards their own learning process. It has developed into the actionoriented approach which views learners as social agents: members of society who have to accomplish (not only) linguistic tasks in a wider social context. According to CEFR (2001) language teaching/learning should embrace both linguistic activities and socio-cultural, pragmatic aspects of interpersonal communication where language is seen as a means to achieve non-linguistic goals. This approach implies more intensive involvement of learners who become conscious of their own needs and internal abilities, they learn by doing, by interacting with other learners (Vygotsky's theory) and by exploring independently the sociocultural reality of a foreign language. In order to achieve such didactic goals, course syllabuses and materials need to be organized on the basis of authentic texts which reveal patterns of actual language within a sociocultural context. Language corpora can be a significant source of a real use of language, providing learners with linguistic, sociocultural and pragmatic data that allow them to analyze lexical and grammatical structures that occur in given real-life situations. Therefore, they can constitute ideal materials for designing didactic activities which can increase the motivation of learners as well. The presentation will attempt to show some action-oriented didactic solutions concerning the use of language corpora in designing teaching/learning activities conducive to more effective language acquisition.
\end{abstract}

\section{Introduction}

Since the advent of communicative approach which focuses primarily on real-life communication acts, on presenting new vocabulary and grammar structures within a given context or theme, language teaching has undergone a pattern shift. The methodology has acquired more interactive and sociocultural dimension entailing an active attitude of learners towards their own learning process. Nevertheless, the communicative approach has not met certain didactic expectations, because of superficial treating of grammar issues and presenting given communicative situations in similar contexts (M. Swan 1985, J. Richards/ T. Rogers 1986). There has been little learners' involvement in their own learning process and not enough learners' cognitive awareness. Recently, foreign language teaching has turned towards more active and interactive patterns which require from learners an independent way of learning based on clear individual objectives to be achieved. The learners have become responsible for their results, constructing their 
knowledge by themselves. Also the role of the teacher has changed, they have become the facilitators of the learning process who do not transfer the knowledge, but support learners to go through consecutive stages in acquiring a target language.

Another important factor which has affected a pattern shift in foreign language teaching is the fast development of mass media, and mostly of the Internet which is one of the most important media of communication. It supports learners both in searching for given information and in observing the real use of language, to the extent that the medium allows. The internet sources offer an unlimited number of linguistic text samples which represent varied discourse styles. Learners have an opportunity to communicate with other learners or native speakers or to observe pragmatic and sociocultural features of communication process, and consequently to acquire the language in an active way (P. Szerszeń 2010: 91-95). Since language corpora became available online, they have begun to play an important role in foreign language teaching because they may be used in order to compose such didactic activities which allow for the observation of real language uses and the development of linguistic, pragmatic and sociocultural competences.

On the other hand, we can notice among teachers the "long-felt dissatisfaction" (B. Kumaravadivelu 2001) with the application of any elaborated didactic method, understood as a way of organizing principles and rules for second or foreign language teaching. Kumaravadivelu describes this situation as an era of post-method pedagogies. According to scholars such as B. Kumaravadivelu (2001), K. Droździał-Szelest, (2013), R. Titone (1968), and H.G. Widdowson (2004) too much attention has been paid to finding the best method and for many years it has not been possible to identify the best teaching method or approach which could be effective in every educational context. The quest for searching the best method became very strong in the second half of the $20^{\text {th }}$ century, when a number of contrastive studies on the efficacy of traditional and modern pedagogical proposals was carried out by different academic centers. Their results do not answer the question which method is superior over the others.

The success of teaching depends on various factors, i.e. a teacher's attitude, learners' individual characteristics, goals to achieve, time devoted to learning, motivation, etc. There is no one effective method that can deliver positive results in all circumstances. Currently, high expectations concerning the notion of method have been supplanted by the new post-method approach involving the connection of certain functional elements derived from different methods in the line with learners' needs and goals. The notion of approach seems to address current language teaching issues better than the notion of method. It refers to a wider context of teaching philosophy, describing a holistic concept of teaching/learning processes, the role of learner and teacher, cultural backgrounds, etc. In contrast, the method is understood as the implementation of a given approach (P. Balboni 2012: 6).

The notion of action-oriented approach described in this paper embraces all the didactic solutions connected with active learning which requires from learners: involvement in the learning process, collaboration with other learners or speakers, tasks which are not too easy and are at an appropriate level of difficulty, while the teacher plays the role of facilitator in the learning process (E. Piccardo 2010). 
Accordingly, the selection of didactic materials and teacher's aids should fulfill these requirements. Using one course book does not suit the actual conditions of the learning/teaching process. In the era of the Internet and rapid sociocultural changes, teachers should avail themselves of a variety of materials and resources which represent a real life language use. But, instead of composing all tasks and activities on their own, they should assign a certain part of work to learners, making them responsible for their own learning process. Learners can both carry out the research on language use and accomplish different tasks which require their active attitude as well as personal involvement in the learning process. Language corpora seem to be an appropriate tool, because they offer real data, varied discourse styles and sociocultural knowledge. The introduction of corpora in a foreign language classroom develops pragmatic competences by showing the context of use of given structures or expressions, it may also enhance the motivation of the students who have an opportunity to work with interesting texts.

This paper attempts to provide certain theoretical and practical tools utilized for applying language corpora in foreign language teaching in line with the action-oriented approach. At the beginning the definition of the approach will be explained, then possible ways of using language corpora in the classroom will be examined. Some examples of such activities are going to be presented, too.

\section{Action-oriented approach: definitions}

According to CEFR (2001) the action-oriented approach "views users and learners of a language primarily as 'social agents', i.e. members of society who have tasks (not exclusively language-related) to complete in a given set of circumstances, in a specific environment and within a particular field of action. While acts of speech occur within language activities, these activities form a part of a wider social context, which alone is able to give them their full meaning" (CEFR 2001: 9). Language action is seen as language tasks accomplished by learners in a given situational context. A learner is supposed to use the target language in order to achieve specific objectives within a given group of (native) speakers. An appropriate use of speech acts involves the sociocultural and pragmatic knowledge. Being engaged in language activities, learners draw on the competences at their disposal and on strategies which seem most appropriate for accomplishing tasks.

A strategy is understood as "any organized, purposeful and regulated line of action chosen by an individual to carry out a task which he or she sets for himself or herself or with which he or she is confronted" (CEFR 2001: 10). A task refers to "any purposeful action considered by an individual as necessary in order to achieve a given result in the context of a problem to be solved, an obligation to fulfill or an objective to be achieved".

Therefore, the language learning/teaching process should aim at developing not only learners' communicative competence but also action strategies that can be undertaken in any kind of circumstances. Learners have to be aware of the necessity to observe the sociocultural context of the target language. All linguistic structures, vocabulary, grammar issues must be presented in appropriate and authentic situations which show their pragmatic value. Learners gain new communicative skills not only by observing, but by interacting with other learners, the teacher or other (native) speakers in diversified situations (external context) (P.M. Lightbown/ N. Spada 2006: 43-44). According to the 
action-oriented approach, the interaction represents one of the most important factors in foreign/second language teaching. Learners acquire new elements by placing them within prior knowledge and competences. New elements must be related to the others. On the other hand, it is important to accompany language learning by learning strategies so that students could apply an adequate strategy to solve a problem, to receive or produce texts, to express given speech acts or to achieve any communicative objective (A. D. Cohen/ S. J. Weaver/ Tao-Yuan Li 1996). Certain strategies and purposeful action can be activated when learners' prior knowledge and competences seem not to be enough to accomplish a task. The ability of choosing the right strategy is crucial in dealing with new situational circumstances. The undertaken action involves drawing on particular competences at learners' disposal; searching and processing new and prior data appropriately for carrying out particular tasks (R. Oxford 1990). To sum up, we may talk about the action-oriented approach when language materials are developed on the basis of authentic situations. The learners are to carry out the tasks which require their personal involvement and creative thinking and the real interaction occurs (meaningful communication) (E. Piccardo 2010: 20-35).

\section{Assumptions about learning}

Generally speaking, the action-oriented approach places language learning within the social context, in which language users carry out communicative tasks by employing given strategies and speech acts. This assumption derives from Vygotsky's socio-cultural theory of cognitive and language development, which in turn arises only in social interaction. The learning process occurs when an individual has an opportunity to interact with an interlocutor within the zone of proximal development (ZPD), especially when the interlocutor represents a higher level of linguistic competences and consequently helps individuals understand and produce texts. Vygotsky's theory can be compared to the interaction hypothesis which involves the mutual support of interlocutors who modify the interaction by making language comprehensible by working together in order to achieve determined goals (P.M. Lightbown/ N. Spada 2006: 43-47). However, Vygotsky emphasized the central role of action in the cognitive development claiming that mental processes undergo a transformation connected with the internalization of social mechanisms. The learner can enhance his or her competences with the help of an expert who explains and facilitates understanding and performing texts in a target language (I. Janowska 2011: 100). The sociocultural theory views producing the language and thinking as two interwoven processes.

\subsection{Active learning}

Except for sociocultural aspects, the action-oriented approach also draws on active learning pedagogies conceived by the American educationalist and philosopher at the beginning of the $20^{\text {th }}$ century - John Dewey (J. Dewey 1938, P. Balboni 2012: 164). In his view the learning process occurs when learners adopt an active attitude and they begin to learn by doing in relation to the principle: "tell me, show me, let me do it by myself". In order to acquire new skills and knowledge learners have to be engaged in activities that require personal involvement, critical reflection upon subject matters and usually collaboration with other learners or language users (M. Żylińska 2013: 38-39, M. Spitzer 
2007: 21). Learning becomes a constructive process in which individuals participate with awareness and in an active way. A linguistic output plays a more significant role in the learning process than a linguistic input (M. Swain 2011). They are mentally and physically involved in varied activities designed by the teacher which implies gathering or processing information, thinking, problem solving, carrying out different projects, peer learning, handling concepts, etc. Learners are not passive recipients of the teacher's action, but they construct meaning, create something new. Active learning should embrace regular assessment of learners' knowledge and competences as well as purposeful recognition and integration of new elements with what the learners already know or use. The learning process might be compared to a jigsaw puzzle which we solve by beginning with a single piece to which we add other pieces. The problem occurs when the teacher does the whole work.

\subsection{Interactive learning}

According to theoretical assumptions, the action-oriented approach assumes that the learning process occurs mostly in a social context. Therefore, it should involve meaningful communication, i.e. an interaction between learners or other speakers in different contexts. One of the most important means that meets that need is collaborative learning "defined as an umbrella term for a variety of educational approaches involving joint intellectual efforts of students and teachers together" (B. Smith/ J. MacGregor 1992). It converges with the interaction hypothesis posited by researchers such as M. Long (1983) and T. Pica (1994). A long affirmed, modified (or simplified) interaction is the mechanism which allows learners to understand a linguistic input. The more frequently learners interact with other speakers, the better they understand the communication process in a target language (N. Spada/ P. Lightbown 2006: 43-47).

Educational settings should give learners an opportunity to work in an interactive way: in groups of two or more so that they could carry out different tasks together. It does not mean that individual work is not effective, but the best way of teaching/learning is based on balancing these two options. Collaborative learning also represents learnercentered approach, in which the teacher adopts the role of the facilitator who designs activities, shows information sources and explains difficult matters when learners negotiate and build their own knowledge and skills. Collaborative activities include exploration and application of course materials, negotiating meaning, discussions, searching for solutions of different problems, carrying out different projects or tasks, working in groups or mutual support. Learners can also avail themselves of the social media to communicate outside the classroom, exchanging materials, information and discussing their problems and difficulties.

\subsection{Involvement}

As has already been emphasized, the action-oriented approach requires mostly an active and involved attitude of students in their own learning process. Mental involvement is a very important condition for acquiring new knowledge and skills. Recent studies in the field of neuroscience suggest that memorizing processes need concentration, active thinking and practical application of new data (M. Spitzer 2007: 59-61). Individual self- 
reliant learning constitutes an important factor affecting the achievement of given learning goals. Undertaking any kind of action requires thinking, choosing the right strategies and engaging knowledge and competences at one's disposal. An involved attitude is connected with doing, thinking and being active. In these circumstances long lasting memorization can occur. According to P. Bogaards (1994: 91-94), the deeper the processing level is, the better we memorize new information. Accordingly, traces in the memory become more solid and permanent if the new data is processed in a purposeful and attentive way. Research shows that the difficulty level has a great influence on the quality of memory traces as well: more difficult tasks lead to better memorization then the easier ones. No teacher is capable of transferring his or her knowledge to learners, who are invited to build their knowledge by themselves.

On the other hand involvement also embraces social relations and interaction with other learners or speakers. Positive learning emotions experienced within social relationships enhance motivation and willingness to learn. It is recommended that learners participate in learning communities in order to consolidate mutual connections and learning achievements.

\subsection{Revising}

According to research on learning mechanisms skills develop very slowly, step by step (M. Spitzer 2002: 59). Learning occurs through exercise and long practice. So, if we really intend to acquire a target language, we need to practise the language as often as possible by using it in varied situational contexts. Course materials, once discussed and analyzed by students, should be revised at a fixed frequency in order to support learners' acquisition. Revising constitutes one of the crucial conditions for effective learning. It always involves connecting what is already known with new elements, which in turn will be reapplied in relation to subsequent elements. Due to this fact, learners have an opportunity to construct new meanings on the basis of their prior knowledge and skills.

\section{Language corpora in foreign language teaching}

Language corpora offer teachers an opportunity to create course materials based on real language. Nowadays, publishing course books needs time and the language is changing so fast as never before. In order to familiarize learners with certain sociocultural, pragmatic or lexical and grammatical issues, teachers may use examples extracted from spoken or written language corpora.

Corpus linguistics and second language teaching have begun to interweave since the early 1990s when researchers noticed many benefits deriving from applying language corpora to pedagogical objectives. We can cite scholars such as: B. Biber, G. Aston, S. Hunston, S. Granger who pointed out a great number of ways in which frequency or register information enriches teaching materials and syllabi. In their view using language corpora may revolutionize the methodology of second/foreign language teaching. It covers all pedagogical areas such as: curriculum design, materials development, teaching approaches and teacher training. Recently, researchers have also become interested in second/foreign language corpora collected from learners in order to identify and analyze learner difficulties, which can be used to improve course materials focused on the most problematic issues. 
Taking into account the possibilities of application of corpus linguistics to pedagogical purposes, the following principal domains can be distinguished:

1) language description - corpus findings allow for revealing real language patterns as well as the frequency data concerning words, collocations or tendencies of certain words to occur together;

2) materials development;

3) corpus analysis in classroom settings: language corpora can be used to design different tasks and activities facilitating language learning. Teachers may invite learners to carry out their own research and to verify the credibility of some structures. There are also more advanced methods such as: calculating statistical data, tagging, parsing, or annotating corpora;

4) learner corpora - display the process of language acquisition, the interlanguage and the effectiveness of teaching methodology.

\subsection{Language description}

In general, language corpora provide different types of data on the real use of collocations, phrasal verbs and other features. They illustrate both the semantic prosody, which means a word connotation determined by its surrounding context and the concept of preferred phraseologies, i.e. the meaning is rather attributed to the entire phrase not to individual words (S. Hunston 2002). These two phenomena seem to be very useful in language teaching, especially in foreign language settings when learners have no direct contact with the target language. Researchers point out that phraseology plays a significant role in language pedagogies.

On the other hand, corpus-based teaching offer an opportunity to analyze grammatical patterns used in given registers or situational contexts. Language corpora constitute formidable data sources concerning specific language genres and certain features that can be explored individually. Using advanced software, researchers (1) identify keywords in domain specific corpora, (2) establish features relevant to given registers, (3) investigate colligation, which is the tendency of certain lexical items to appear at the beginning, in the middle or at the end of text.

\subsection{Materials development}

Language corpora offer different data and real use language samples that can be applied to develop course materials and teacher-made handouts. Teachers can design activities in order to increase the motivation of learners, to encourage them to work in an independent or collaborative way and to show real language uses. A corpus-based curriculum includes vocabulary frequency lists and statistically relevant information. As far as spoken language is concerned, corpora provide samples of real speeches, dialogues or other genres which allow students to observe the appearance of discursive markers, pragmatic and sociocultural features. The observation should be followed by learners' active learning which involves applying the analyzed linguistic elements in activities such as roleplaying, filling gaps, tagging, searching for new data, describing or categorizing new items, etc. Corpus-based handouts might constitute an important information source and practically speaking, their preparation requires very little teachers' workload (once in a 
while they only need to stamp concordance lines or the results of keyword search). Besides the observation, learners are invited to discuss revealed linguistic elements to negotiate their meaning, describe them and finally reapply them in new contexts. Language corpora offer teachers a variety of activities to be carried out inside or outside the classroom. They should not be afraid of including them into teaching programmes. Their application seems reasonable in case of language for specific purposes or translation courses at advanced proficiency levels. However, corpora can also be introduced into courses for beginners, it is only a matter of adequate materials selection (C.M. Keck 2004: 89-92).

Another significant advantage offered by corpus-based teaching concerns grammatical matters. On the basis of real examples learners have an opportunity to understand grammar patterns, parse sentences and tag given elements. Although, researchers such as B. Biber et al. (1999), S. Hunston (2002) point out the difficulty that results from the existence of competing approaches to language description within corpus linguistics. Therefore, the decision as to which approach to choose for a given course must be taken individually by a teacher.

\subsection{Corpus analysis in classroom settings}

Researchers highlight another important aspect of corpus-based teaching, active and involved learning which embraces two possible methods: (1) teacher directed data-driven and (2) student-led discovery learning. Both of them attempt to develop learners' autonomy over teacher's authority (G. Aston 2001, L. Burnard/ T. McEnery 2000).

The first approach which posits a leading role of a teacher, introduced by T. Johns (1991), engages learners in the analysis of materials arranged by the teacher in order to draw their attention to certain features. Learners' task is to reveal and understand given structures or expressions and then to reuse them in other contexts. Such activities may be based on concordance lines which show the research results of selected words or phrases applied to design different activities. The application of concordance lines develops learners' bottom-up processing skills. Another example of teacher directed handouts is collecting parallel corpora which include texts in the target language and their translation in the first or another language. It allows learners to observe how given elements can be realized in two different languages. In the case of learners coming from different language backgrounds, parallel corpora offer an opportunity to observe different ways of expressing one meaning.

Student-led discovery learning implies more active attitude of learners who become authors of their learning process. A teacher is not responsible for preparing materials any more, but it is the learners who generate them by themselves. Autonomous discovery learning invites them to carry out their own research on given features by using different corpora that might be indicated by the teacher. This approach mostly enhances the motivation, because learners have a possibility of making discoveries and exploring language data in search of relevant information. The Italian researcher D. Zorzi (2001) provides a very interesting example of students' investigation concerning the use of discourse markers in Italian. Additionally, students could gain the pragmatic knowledge about the relation between the contexts in which these elements appear and their meaning. Zorzi carried out her study on the basis of LIP (Corpus of Italian Spoken Language). 
Discovery learning also embraces collecting corpora by learners who are asked to search and select texts on a given theme. This activity may constitute a part of the whole project that involves not only developing a corpus, but also interpreting data and making generalizations about the language use.

In conclusion, it has to be emphasized that effective discovery learning requires expertise and involvement from both teachers and learners in selecting, using or developing language corpora. Taking into account the credibility of corpus-based teaching, two important issues have to be pointed out: generalizability and representativeness of language corpora. The first notion refers to possible generalization of revealed features to the language as a whole system, the second one implies that a corpus should include an appropriate number of text samples belonging to a given domain of use (C.M. Keck 2004: 95).

\subsection{Learner corpora}

For the last three decades corpus linguistics and second/foreign language teaching have interwoven, but the creation of learner corpora have enabled researchers to carry out relevant interlanguage studies whose findings demonstrate the development of acquisition process over time (S. Granger, J. Hung/ S. Petch-Tyson 2002). Learner corpora consist of (1) collections gathered in authentic contexts: classroom activities, (2) continuous stretches of discourse (not isolated sentences or words), (3) compilations gathered using strict design criteria, (4) compilations for a specific SLA or FLT purpose. Linguistic data revealed in learner corpora have been implemented to describe the interlanguage, develop teaching materials and activities/tasks and, above all, train future teachers (S. Granger et al. 2002). Recently, interlanguage studies have focused both on contrastive analyses between the learner's language and the native speaker's language and comparisons made between learners of the target language deriving from different cultural backgrounds. Findings show how learners use or overuse particular linguistic elements or how they deviate from native speaker's productions, which helps to indicate areas of possible first language (L1) transfer or interference. Researchers emphasize the necessity of investigation on the magnitude of differences in order to identify the most problematic linguistic issues for given groups of learners. Additionally, the analysis of learners' typical errors allows for better materials development and curriculum design adapted for learners' needs. Applying learner corpora in the classroom is also recommended so that students could analyze and compare their interlanguage with native speakers' data. This type of activity promotes learning autonomy and independence, because students have an opportunity to reflect on their production and on frequently occurring mistakes. The awareness of their own limits and deviations from native speakers' patterns is a necessary condition of progress. Researchers also focus on differences in the target language productions among learners coming from distinct cultural backgrounds.

\section{Action-oriented approach to corpus linguistics in FLT}

The action-oriented approach assumes that the learning process implies (1) interaction (between learners, learners and their teacher, learners and other speakers), (2) learners' involved and their active attitude, (3) collaboration (4) critical thinking (5) deep cognitive processing including organizing and integrating new elements with the known ones, (6) frequent revising. Most of all, it attempts to enhance sociocultural and pragmatic 
competences as well as learning and action strategies in order to promote learners' autonomy and their independent thinking.

The interface between corpus linguistics and foreign language teaching addresses the requirements of the action-oriented approach. On one hand, language corpora provide teachers with formidable real language data that might be analyzed in the classroom, on the other hand they invite learners to carry out their own research projects on given features. They promote discovery learning by inviting learners to search on their own for certain grammatical patterns, collocations, lexical items, etc. This part of the paper will provide some practical examples of the use of corpora in a foreign language classroom.

\subsection{Learning vocabulary and collocations}

In competitive groups students are asked to indicate the top 3 object nouns used with given verbs, then they may write down sentences with these collocations which will be checked against the corpus and text samples. The winner is the group which has chosen the most popular nouns.

1) Indicate the top 3 nouns used with the verb TO RAISE + ..., then write down sentences with these collocations. Check your solutions against the corpus.

ISSUES/ POWER/ AWARENESS/ CHILDREN/ GLASSES/ MONEY/ ARM/ STANDARDS/ HANDS/ OBJECTION/ FUNDS/ INCOME

2) Choose the most frequent adjectives used with the noun RAISE: A [adj.] RAISE. SUITABLE/ ADDITIONAL/ SLIGHT/ HIGH/ YEARLY/ SPECIAL/ EXTRA

Another collaborative task involves searching for collocations with nouns or verbs, then checking the results against concordance lines. The first group looks for adjectives used with the noun JOB. The second group has to establish which verbs are usually used with this noun. In order to complete the task, the students have to identify appropriate parts of speech in frequency lists. They compile the lists with the top ten words

Afterwards, the students give them to the teacher. A representative of each group says two numbers, the teacher reads two words and the student has 3 minutes to create a sentence containing these elements. If $\mathrm{s} /$ he is not able to do it, their team loses a point. This kind of activity allows students to learn not single words but entire language chunks ${ }^{1}$.

\subsection{Learning pragmatics}

According to G. Kasper (2002: 340) learners may acquire pragmatic competences in two ways: the first one represents a planned pedagogical action, the second one involves exposure to input without any purposeful instruction. Language corpora address both types of classroom learning because, on one hand, they offer interesting and motivating input, on the other hand they constitute formidable sources for designing activities aimed at developing pragmatic skills. The Italian linguist, D. Zorzi has proposed an activity focusing on the meaning of Italian discourse markers in given contexts (2001). She used

\footnotetext{
${ }^{1}$ More examples of such activities are presented on the website: https://www.etprofessional.com/5_ways_to_use_the_corpora_for_classroom_activities_84418.aspx
} 
one of the most important collections of texts of spoken Italian: LIP (Lessico di frequenza dell'italiano parlato) for her study, which consists of many text samples including conversations at home, work, school, telephone conversations, legislative assemblies, cultural discussions and others.

Spoken language corpora constitute a perfect means to enhance pragmatic and sociocultural competences. They offer real language text samples whose analysis allows learners to observe the meaning of elements within a certain linguistic environment.

The tasks that may be designed in different and interesting ways. D. Zorzi invites students to observe and investigate the meaning of discourse markers within a given situational context or the realization of certain speech acts on the basis of concordance lines, which in turn may be used as a preparatory phase of guided analysis before starting less-controlled exercises. The teacher may assign each group the analysis of different markers so that they could work in a collaborative way and then present or discuss together the results of research. They are asked to formulate a hypothesis about the meaning of discourse markers in given communicative circumstances or to indicate their pragmatic function. In addition, students can work on chosen speech acts in order to observe their structure and the context of use. Acquiring pragmatic competences is one of the most important objectives in foreign language curriculum (G. Kasper/ K. R. Rose 2002). As a summary task devoted to developing fluency, the teacher may remove certain markers from the text asking students to fill in the gaps with possible elements and then discuss semantic differences between them.

Teachers may collect their own corpora or may assign this task to students determining a particular domain or a text type in order to meet particular learners' needs. In the case of translation courses it is recommended to compile parallel corpora that include the target language text samples and their translations in the first or other languages. This type of task allows learners to observe how specific linguistic features are realized in different languages.

\section{Conclusion}

The target language corpus-based teaching provides many benefits for learners and teachers. The use of language corpora seems to meet the requirements of action-oriented approach allowing learners both to observe the real communication contexts and carry out their own research which obviously supports memorizing new data. In addition, it enhances curriculum design by enriching course materials with words, collocations or other real language examples. It also offers a great number of tasks and activities which develop the independence and autonomy of learners in line with the action-oriented approach.

But first of all, corpus-based teaching develops sociocultural and pragmatic competences throughout the presentation of register variations, realization of speech acts, the use of discourse markers and collocations. Learners have an opportunity to explore language data, i.e. the frequency of given words or features, their statistical significance and grammatical structures in use. They may collect parallel corpora that include texts and their translation in other languages, e.g. translations of phrases displayed in concordance lines into the first language in order to see the differences in realization of given features between two languages. 
Accordingly, learner corpora allow us:

1) to identify learners' difficulties;

2) to adjust course materials to learners' proficiency level;

3) to establish the acquisition level, the pace of acquisition process over time, current needs and gaps that should still be filled.

4) to carry out the contrastive analysis between different groups of learners;

5) to prepare tests and evaluation tasks.

Language corpora constitute a very important means of improving teaching materials. Currently, as one perfect teaching method suitable for every educational context cannot been applied the crucial issue is to teach learners how to learn in an effective way to show them strategies and resources which may help them to enhance communicative competences by themselves.

\section{References}

Aston, G. (2001), Learning with corpora. Houston.

Balboni, P. (2012), Le sfide di Babele. Insegnare le lingue nelle società complesse. Torino.

Biber, B./ S. Johansson / G. Leech / S. Conrad /E. Finegan (1999), Longman Grammar of Spoken and Written English. London.

Bogaards, S. (1994), Le vocabulaire dans l'apprentissage des langues étrangères, Paris.

Burnard, L./ T. McEnery (2000), Rethinking language pedagogy from a corpus perspective. New York.

Cohen, A.D./ S.J. Weaver / Li Tao-Yuan (1996), The impact of strategies-based instruction on speaking a foreign language. Research Report. Center for Advanced Research on Language Acquisition: University of Minnesota.

Council of Europe. (2001), Common European framework of reference for languages: learning, teaching, assessment. Strasbourg.

Dewey, J. 1938. Experience and Education. New York.

Droździał-Szelest, K. (2013), Methods in Language Teaching: Do We Still Need Them? In: K. Droździał-Szelest/ M. Pawlak (eds.), Psycholinguistic and Sociolinguistic Perspectives on Second Language Learning and Teaching. Heidelberg, 177-197.

Granger, S./ J. Hung / S. Petch-Tyson (2002), Computer learner corpora, second language acquisition and foreign language teaching. Philadelphia: John Benjamins.

Hunston, S. (2002), Corpora in applied linguistics. Cambridge.

Janowska, I. (2011), Podejście zadaniowe do nauczania i uczenia się języków obcych. Na przykładzie języka polskiego. Kraków.

Johns, T. (1991), Should you be persuaded: two examples of data-driven learning. In: T. Johns/ P. King (eds.), Classroom concordancing. ELR Journal Vol. 4, Birmingham, 1-16.

Kasper, G./ K.R. Rose (2002), The role of instruction in learning second language pragmatics. In: L. Ortega (ed.), Second Language Acquisition. Critical Concepts in Linguistics. Volume I. London/ New York, 340-367. 
Keck, C.M. (2004), Corpus linguistics and language teaching research: bridging the gap. In: Language Teaching Research 8,1, 83-109.

Kumaravadivelu, B. (2001), Toward a Post-method Pedagogy. In: TESOL Quarterly 35/4, 537-560.

Lightbown, P.M./ N. Spada (2006), How languages are learned. Oxford.

Long, M. (1996), The role of the linguistic environment in second language acquisition. In: W. Ritchie/ T. Bhatia (eds.), Handbook of Second Language Acquisition. Bingley, 413-468.

Oxford, R. (1990), Language learning strategies: What every teacher should know. Boston.

Pica, T. (1994), Research on Negotiation: What does it Reveal about Second Language Learning Conditions, Processes and Outcomes? In: Language Learning 44, 493527.

Piccardo, E. (2010), From communicative to action-oriented: new perspectives for a new millennium. In: TESL Ontario Contact 36(2), 20-35.

Richards, J.C./ T. Rogers (1986), Approaches and Methods In Language Teaching. A description and analysis. Cambridge.

Smith, B.L./ J.T. MacGregor (1992), What is Collaborative Learning? In: A. Goodsell/ M. Maher (eds.), A Sourcebook for Higher Education, Pennsylvania State University [accessed 17.06.2015]

Spitzer, M. (2007), Jak uczy się mózg. Warszawa.

Swain, M. (2011), Communicative Competence. Some roles of comprehensible input and comprehensible output in its development. In: L. Ortega (ed.), Second Language Acquisition. Critical Concepts in Linguistics. Volume I. London/ New York, 139160.

Swan, M. (1985), A critical look at the communicative approach. In: English Language Teaching Journal 39 (1), 2-12.

Szerszeń P. (2010), Glottodydaktyka a hiperteksty internetowe. Warszawa.

Titone, R. (1968), Teaching foreign languages. A historical sketch. Washington.

Widdowson, H.G. (2004), A perspective on recent trends. In: A.P.R. Howatt/ H.G. Widdowson (eds.), A history of English language teaching. Oxford, 353-372.

Zorzi, D. (2001), The pedagogic use of spoken corpora: learning discourse markers in Italian. In: G. Aston (ed.), Learning with corpora. Houston, 85-107.

Żylińska, M. (2013), Neurodydaktyka. Nauczanie i uczenie się przyjazne mózgowi. Toruń. 